\title{
Pengaruh Modul Pemberdayaan Keluarga tentang Toilet Training terhadap Kemandirian Eliminasi Anak di PAUD
}

\author{
Iryanti, Kamsatun \\ Jurusan Keperawatan, Poltekkes Kemenkes Bandung \\ Email: iryanti_natadiredja@yahoo.com
}

\begin{abstract}
Abstrak
Anak prasekolah harusnya dapat mengontrol BAB/BAK secara mandiri, namun berdasarkan survey kesehatan rumah tangga nasional, 75 juta anak prasekolah susah mengontrol BAB/BAK, sehingga anak mengompol dan buang air besar di celana, keadaan tersebut bila berlangsung lama akan mengganggu tugas perkembangan anak. Keluarga menentukan keberhasilan anak BAB/BAK di toilet, sehingga pengetahuan,sikap, dan keterampilan keluarga mengenai toilet training menjadi penting. Penelitian ini menganalisis pengaruh modul pemberdayaan keluarga tentang toilet training terhadap kemandirian eliminasi anak. Jenis quasi experiment, pre-post test two group design. Sampel sebanyak 58, yaitu 29 subjek kelompok perlakuan dan 29 subjek kelompok kontrol, diambil dengan multi stage random sampling. Lembar observasi digunakan untuk mengukur kemandirian eliminasi anak, variabel tersebut diukur sebelum dan sesudah keluarga diberi modul toilet training untuk digunakan melatih anaknya selama 4 minggu. Data dianalisis dengan uji T independent. Hasil uji statistik menunjukkan kemandirian eliminasi BAB/BAK anak di toilet pada kelompok perlakuan lebih baik daripada kelompok kontrol $(\mathrm{p}$-value $=0,000)(\mathrm{p}<0,05)$. Simpulan penelitian ini bahwa penggunaan modul toilet training oleh keluarga meningkatkan kemandirian eliminasi anak BAB/BAK di toilet. Disarankan bagi keluarga dan PAUD, agar anak umur prasekolah yang belum bisa BAB/BAK secara mandiri dikoreksi secara dini dengan toilet training secara benar dan intensif agar anak dapat tumbuh dan berkembang secara optimal.
\end{abstract}

Kata kunci: Anak, kemandirian eliminasi, modul, toilet training.

\section{The Effect of Family Empowerment regarding Toilet Training Module towards Children's Independence for Toileting in PAUD (Early Child Education)}

\begin{abstract}
Pre-school children should be able to control urination/defecation independently, however, based on national household health survey 75 million of pre-school children were difficult to control their urination/defecation, so that they urinated and defecated in their pants. These conditions, if happened in prolonged time, would impair the development tasks of the children. Families determine the success of children toilet training. Therefore, knowledge, attitude, and skills of the families regarding toilet training are important. This study analyzed the effect of the module of family empowerment regarding toilet training towards the independence of toileting among children. Quasi-experiment with pre-posttest two group design was used. The sample of 58 participants, which divided into 29 participants in intervention group and 29 participants in control group, were recruited using multi stage random sampling. Observation sheet were used to measure the children's independence for toileting, this variable were measured before and after the families were given toilet training module to train the children for 4 weeks. The data were analyzed using t-independent. The results showed that the children's independence in toileting were better in the intervention group compared to the control group $(p$-value $=0.000)$ $(p<0.05)$. The conclusion of this study is that the use of toilet training module by the families can increase the children's independence in toileting. It is suggested for families and early child education to provide toilet training for children as early as possible in a right way intensively so that the children can grow and develop optimally.
\end{abstract}

Keywords: Children, module, toileting independence, toilet training. 
Iryanti: Pengaruh Modul Pemberdayaan Keluarga tentang Toilet Training

\section{Pendahuluan}

Pembangunan kesehatan sebagai bagian dari upaya membangun manusia seutuhnya antara lain diselenggarakan melalui upaya kesehatan anak. Upaya kesehatan yang dilakukan pada lima tahun pertama (balita) kehidupan, ditujukan untuk meningkatkan kualitas hidup anak agar mencapai tumbuh kembang optimal (Kementerian Kesehatan Republik Indonesia (Kemenkes RI), 2012).

Menurut Kemenkes RI (2012), otak balita lebih plastis. Plastisitas otak pada balita mempunyai sisi positif dan negatif. Sisi positifnya, otak balita lebih terbuka untuk proses pembelajaran. Sisi negatifnya, otak balita lebih peka terhadap lingkungan utamanya lingkungan yang tidak mendukung seperti kurang stimulasi atau latihan. Oleh karena masa lima tahun pertama kehidupan merupakan masa yang sangat pendek serta tidak dapat diulang lagi, maka masa balita disebut masa kritis. Masa ini dibagi menjadi 3 periode, yaitu: masa bayi umur 0 sampai 11 bulan, masa toddler umur 12 sampai 36 bulan, masa prasekolah umur 36 sampai 60 bulan. Menurut Andriana (2011), pada masa ini diperlukan stimulasi atau latihan agar potensi anak berkembang.

Masa toddler terjadi perkembangan kemampuan mengenali rasa untuk mengeluarkan dan menahan eliminasi serta mampu mengomunikasikan sensasi BAB/ BAK kepada orang tua (Alexandra, 2008 dan Klijn, 2006). Menurut Keen et al., (2007) dan Wald, (2009), latihan eliminasi merupakan suatu usaha untuk melatih anak agar mampu mengontrol BAB/BAK. Latihan tersebut dapat dilaksanakan pada anak yang sudah memasuki fase kemandirian. Fase ini biasanya terjadi pada anak umur antara 18-24 bulan (Ritblatt et al., 2003 dalam Mota dan Barros, 2008). Keberhasilan toilet training bisa dilihat pada akhir umur 3 tahun. Anak umur prasekolah seharusnya sudah dapat mengontrol BAB/BAK, namun berdasarkan hasil survey kesehatan rumah tanggga (SKRT) nasional diperkirakan balita yang susah mengontrol $\mathrm{BAB} / \mathrm{BAK}$ sampai umur prasekolah mencapai 75 juta anak. Kegagalan mengontrol BAB/BAK mengakibatkan anak mengompol dan berak dicelana. Keadaan tersebut apabila berlangsung lama akan mengganggu tugas perkembangan anak. Sejalan dengan penelitian Kurniawati tahun 2008 , yang menyebutkan bahwa 56 persen anak prasekolah masih sering mengompol. Fenomena ini dipicu antara lain karena pengetahuan ibu yang kurang tentang cara melatih BAB/BAK, pemakaian popok sekali pakai, hadirnya saudara baru (Ritblatt, 2003 dalam Pusparini, 2010).

Dampak tidak diterapkannya latihan eliminasi diantaranya anak keras kepala, susah diatur, tidak mandiri, dan masih membawa kebiasaan mengompol hingga besar. Selain itu, ketidakberhasilan dalam latihan eliminasi akan membuat anak mengalami kepribadian eksprensif dimana anak akan lebih tega, cenderung ceroboh, suka buat gara-gara, emosional, dan seenaknya dalam melakukan kegiatan sehari-hari (Hidayat, 2009).

Menurut Kemenkes RI (2012), intervensi dini penyimpangan perkembangan adalah tindakan tertentu pada anak yang perkembangan kemampuannya tidak sesuai dengan umurnya. Tindakan intervensi dini tersebut berupa stimulasi perkembangan terarah yang dilakukan secara intensif di rumah selama dua minggu. Sedangkan menurut Schmitt (1991 dalam Hidayat, 2010), latihan eliminasi dilakukan dalam dua sampai delapan minggu. Keberhasilan latihan eliminasi tidak hanya dipengaruhi oleh kemampuan anak tetapi juga perilaku orang tua dalam mengajarkan latihan eliminasi secara baik dan benar (Warner dan Paula, 2007 dan Barone, 2009).

Keluarga salah satunya ibu, merupakan tokoh sentral dalam perkembangan anak prasekolah. Ibu perlu dibekali pengetahuan dan keterampilan agar mengerti dan terampil dalam melaksanakan pengasuhan anak khususnya latihan eliminasi, sehingga dapat bersikap positif dalam membimbing tumbuh kembang anak secara baik. Penelitian Syahid (2009), 63,8 persen tingkat pengetahuan ibu tentang latihan eliminasi tidak baik, dan 56,4 persen ibu tidak menerapkan latihan eliminasi. Terdapat hubungan antara tingkat pengetahuan ibu dengan penerapan latihan eliminasi anak umur 1-3 tahun.. Notoatmodjo, (2003 dalam Wijayanti dan Purwandari, 2006) mengatakan bahwa pengetahuan merupakan domain yang sangat penting untuk terbentuknya tindakan 
Iryanti: Pengaruh Modul Pemberdayaan Keluarga tentang Toilet Training

seseorang. Modul telah terbukti efektif dalam meningkatkan pengetahuan, sikap, dan keterampilan tentang promosi farmasi (Shankar et al., 2012).

Pengetahuan dan keterampilan dapat diperolehmelalui pembelajaranmodul, karena pada dasarnya pembelajaran melalui modul adalah belajar secara mandiri (Sungkono, 2013). Hasil penelitian Ammelda, dkk. (2015), menyimpulkan bahwa Modelling media video dan gambar berpengaruh terhadap peningkatan kemampuan toilet training pada anak toddler $p$-value $=0,02(p$ value $<\alpha)$. Perbedaan penelitian ini dengan penelitian Ammelda dkk adalah populasinya anak umur prasekolah dan menghasilkan produk berupa modul tentang toilet training. Hasil studi pendahuluan tanggal 16 September 2014 di salah satu PAUD di Kota Bandung, dari delapan ibu yang mempunyai anak umur 4-5 tahun, 5 ibu tidak mendampingi anak saat $\mathrm{BAB} / \mathrm{BAK}$, didapatkan empat anak masih $\mathrm{BAB} / \mathrm{BAK}$ di celana, sedangkan tiga ibu yang mendampingi anak saat $\mathrm{BAB} /$ $\mathrm{BAK}$, dua diantaranya masih $\mathrm{BAB} / \mathrm{BAK}$ di celana. Dari data tersebut enam anak masih mengompol dicelana baik siang maupun malam hari, sedangkan $\mathrm{BAB}$ ke enam anak sudah mengenali tanda mau berak tetapi belum bisa cebok sendiri. Menurut Alexanda (2008) dan Klijn (2006), pada perkembangan normal akhir umur 3 tahun anak bisa $\mathrm{BAB} / \mathrm{BAK}$ secara mandiri di toilet, dan menurut Kroeger (2010) dan Horn (2006), mengompol yang terjadi pada anak yang berumur lebih dari empat tahun tanpa adanya kelainan fisik atau pun penyakit organik merupakan gangguan. Melakukan intervensi dini terhadap gangguan tumbuh kembang balita artinya melakukan tindakan koreksi, agar gangguan tidak semakin berat.

Latihan eliminasi sangat penting dilakukan, namun intervensi keperawatan tersebut belum banyak dilakukan di masyarakat dan belum ada modul khusus tentang toilet training. Kota Bandung memiliki anak umur prasekolah sebanyak 30 persen dari total populasi, sehingga sebagai calon generasi penerus bangsa, kemandirian anak umur prasekolah perlu mendapat perhatian serius. Berdasarkan hal tersebut penelitian ini penting dilakukan untuk menghasilkan modul dan memotivasi keluarga, agar melakukan toilet training sebagai upaya dalam mempersiapkan anak menjadi generasi penerus yang mandiri.

\section{Metode Penelitian}

Penelitian ini merupakan penelitian Quasy Experimental dengan pretest-posttest two group design (Grove et al., 2013). Penelitian ini melibatkan dua kelompok yaitu kelompok perlakuan yang diberi intervensi, dan kelompok kontrol tidak diberi intervensi (intervensi diberikan setelah penelitian selesai). Pada masing-masing kelompok dilakukan pengukuran sebelum diberikan intervensi (pretest) dan setelah diberikan intervensi (posttest). Variabel independen adalah modul pemberdayaan keluarga tentang toilet training, variabel dependen adalah kemandirian eliminasi anak, dan variabel antara adalah pengetahuan, sikap, dan keterampilan keluarga. Penelitian dilaksanakan di PAUD Kota Bandung, pada bulan Juli - September 2015.

Populasi adalah anak PAUD di Kota Bandung yang berjumlah 4640 anak pada 232 PAUD, besar sampel berdasarkan rumus Lemesshow et al., (1997 dalam Suyatno, 2010), didapatkan kelompok perlakuan 29 anak, dan kelompok kontrol 29 anak. Sampel diambil menggunakan multi stage random sampling, dimana Kota Bandung terdiri dari 30 kecamatan disetiap kecamatan terdapat PAUD dengan karakteristik yang hampir sama, maka ke 30 kecamatan tersebut diundi dan terpilih Kecamatan Cicendo.

Kecamatan Cicendo terdiri dari 6 kelurahan yang tiap kelurahan memiliki PAUD, agar kelompok kontrol tidak terpapar kelompok perlakuan, maka masing-masing kelompok dilaksanakan di kelurahan yang berbeda. Setelah diundi Kelurahan Pasirkaliki terpilih sebagai kelompok perlakuan dan Kelurahan Pamoyanan sebagai kelompok kontrol. Adapun kriteria sampel adalah: 1) anak umur antara 36 bulan sampai dengan 60 bulan dan masih BAB/BAK dicelana; 2) anak tidak cacat fisik dan mental; 3) anak tidak menggunakan popok sekali pakai; 4) anak tinggal dengan keluarga inti; 5) pendidikan orang yang dominan dalam pengasuhan anak non kesehatan; 6) keluarga bisa baca dan tidak pikun. Dari 63 anak di PAUD Kelurahan 
Iryanti: Pengaruh Modul Pemberdayaan Keluarga tentang Toilet Training

Pasir Kaliki 29 anak memenuhi kriteria, dan dari 56 anak di PAUD Kelurahan Pamoyanan 29 anak yang memenuhi kriteria. Setelah 58 keluarga atau orang yang dominan dalam pengasuhan anak diberi dan menandatangani informed consent, peneliti memberitahukan keluarga agar pada saat penelitian anak tidak menggunakan popok sekali pakai.

Sebelum diberikan intervensi (pretest), keluarga pada kelompok perlakukan dan kelompok kontrol dipersilahkan mengisi kuesioner pengetahuan dan sikap selama 30 menit, dilanjutkan dengan mengobservasi keterampilan keluarga dan kemandirian eliminasi anak dengan mewawancarai keluarga atau orang yang dominan dalam pengasuhan anak dengan menggunakan lembar observasi. Kuesioner dan lembar observasi keterampilan keluarga adalah valid dan reliabel, karena uji validitas kuesioner pengetahuan, sikap, dan keterampilan keluarga didapatkan nilai $r$ hitung $>0,632$ , dan hasil uji realibilitas didapatkan nilai $\mathrm{r}$ hitung $>0,9$. Lembar observasi kemandirian eliminasi tidak dilakukan uji validitas dan realibilitas, karena aspek yang diobservasi sesuai langkah-langkah kemandirian eliminasi anak BAB/BAK di toilet.

Kemudian peneliti melatih keluarga kelompok perlakuan cara menggunakan modul toilet training selama 2 hari, materi hari ke 1 yaitu konsep dan demonstrasi toilet training, hari ke 2 redemonstrasi toilet training oleh keluarga. Media pelatihan yaitu LCD dan modul yang disusun peneliti. Adapun materi yang dimuat dalam modul toilet training meliputi: pengertian, tujuan, keuntungan, waktu, pentingnya, faktor yang mendukung, tahapan latihan, cara melatih, tips dalam melatih, kunci keberhasilan latihan, faktor pendukung lain latihan $\mathrm{BAB} / \mathrm{BAK}$, faktor penghambat, tips untuk memulai latihan, dasar-asar latihan BAB/ BAK. Modul ini dibuat untuk memudahkan keluarga dalam melatih toilet training pada anaknya di rumah. Alat untuk toilet training menggunakan toilet yang ada di PAUD dan yang ada di rumah masing-masing, sedangkan pakaian dan celana menggunakan kepunyaan anaknya sendiri.

Selesai pelatihan keluarga kelompok perlakuan diberi modul tentang toilet training untuk digunakan melatih anaknya
$\mathrm{BAB} / \mathrm{BAK}$ di toilet setiap kali anak $\mathrm{BAB} /$ BAK baik di rumah maupun di sekolah selama 4 minggu, setelah 1 minggu, peneliti mengobservasi keluarga di bantu guru PAUD dan memberikan tutorial yang ke 2 dengan menggunakan modul yang sama, tutorial dilakukan sebanyak 3 kali selama penelitian yaitu akhir minggu ke 1, 2, dan 3.

Akhir minggu ke 4 dilakukan Posttest pada kelompok perlakuan dan kelompok kontrol dengan menggunakan instrumen yang sama. Selama proses penelitian kelompok kontrol tidak diberikanintervensiapapun tetapi setelah penelitian selesai kelompok kontrol diberi modul dan dilatih cara menggunakannya. Untuk menganalisis kemandirian eliminasi anak, dan pengetahuan, sikap, keterampilan keluarga sebelum dan sesudah diberikan modul tentang toilet training pada kelompok perlakuan dan kelompok kontrol digunakan uji $t$ dependent, untuk menganalisis pengaruh modul pemberdayaan keluarga tentang toilet training terhadap kemandirian eliminasi anak, digunakan uji $t$ independent dengan keputusan uji bila $p$-value $<\alpha(0,05)$ maka secara statistik terdapat pengaruh yang bermakna, apabila $p$-value $>\alpha(0,05)$ tidak ada pengaruh yang bermakna. Sedangkan untuk menganalisis hubungan pengetahuan, sikap, dan keterampilan keluarga setelah diberi modul tentang toilet training dengan kemandirian eliminasi anak digunakan analisis logistik linier.

Satu sampel drop out karena pada saat dilakukan pengumpulan data post perlakuan, orang yang dominan mengasuh anak melahirkan di luar kota di rumah orang tuanya, sehingga jumlah sampel akhir kelompok perlakuan 28 anak dan kelompok kontrol 28 anak.

\section{Hasil Penelitian}

Penelitian dilakukan pada tanggal $27 \mathrm{Juli}$ sampai dengan 5 September 2015. Sampel penelitian kelompok perlakuan sebanyak 28 keluarga dan kelompok kontrol sebanyak 28 keluarga, lama pelaksanaan pemberdayaan keluarga melalui modul toilet training dilakukan selama 4 minggu. Berikut adalah deskripsi data hasil analisis pada kondisi baseline dan intervensi. 
Iryanti: Pengaruh Modul Pemberdayaan Keluarga tentang Toilet Training

Kondisi baseline merupakan pengamatan terhadap kemandirian eliminasi anak, dan pengetahuan, sikap, serta keterampilan keluarga tentang toilet training sebelum diberi intervensi pada kelompok perlakuan dan kelompok kontrol. Data kondisi baseline kelompok perlakuan, rerata nilai kemandirian eliminasi anak adalah 66,3, dan pengetahuan adalah 61,6 , sikap adalah 72,1, keterampilan keluarga dalam melakukan toilet training adalah 60,4. Sedangkan pada kelompok kontrol, rerata nilai kemandirian eliminasi anak adalah 63,7, pengetahuan adalah 63,4, sikap adalah 74,8, dan keterampilan keluarga dalam melakukan toilet training adalah 62,1. Untuk lebih jelasnya data tersebut dapat dilihat pada tabel 1 .

Pada kondisi baseline, hasil uji Skewness yaitu untuk melihat normal tidaknya data dilihat dari nilai Skewness dibagi standar eror jika nilai $<2$ maka data berdistribusi normal (Hastono, 2007). Hasil uji didapatkan nilai kemandirian eliminasi anak, dan pengetahuan, sikap, keterampilan keluarga $<$ 2 artinya data tersebut merupakan data yang berdistribusi normal.

Kondisi intervensi merupakan pengamatan terhadap kemandirian eliminasi anak, dan pengetahuan, sikap, keterampilan keluarga tentang toilet training setelah diberikan perlakuan. Data kondisi intervensi kelompok perlakuan, rerata nilai kemandirian eliminasi anak adalah 90,5, dan pengetahuan adalah 77,1 , sikap adalah 82,9 , keterampilan keluarga dalam melakukan toilet training adalah 94,6. Sedangkan pada kelompok kontrol, rerata nilai kemandirian eliminasi anak adalah
70,9, dan pengetahuan adalah 57,3, sikap adalah 71,2, keterampilan keluarga dalam melakukan toilet training adalah 70,4. Untuk lebih jelasnya data tersebut dapat dilihat pada tabel 1.

Hasil analisis dalam kondisi pada setiap komponennya dapat dijabarkan sebagai berikut: kemandirian eliminasi anak, dan pengetahuan, sikap, keterampilan keluarga tentang toilet training sebelum diberikan modul, pada kelompok perlakuan dan kontrol menunjukkan rerata nilai yang hampir sama, akan tetapi setelah diberi modul, pada kelompok perlakuan rerata nilai kemandirian eliminasi anak 30,2, dan pengetahuan 15,5, sikap 10,8, keterampilan keluarga 34,2 lebih tinggi dibandingkan sebelum diberi modul. Sebaliknya pada kelompok kontrol rerata nilai kemandirian eliminasi anak 7,2, dan pengetahuan 6,1 dan sikap 3,6 lebih rendah, kecuali keterampilan keluarga 8,3 lebih tinggi, namun dibandingkan dengan kelompok perlakuan kenaikan keterampilan keluarga jauh lebih baik pada kelompok yang diberi modul

Hasil uji normalitas didapatkan data terdistribusi normal, sehingga untuk menganalisis kemandirian eliminasi anak, pengetahuan, sikap, dan keterampilan keluarga sebelum dan sesudah keluarga diberi modul pada kelompok perlakuan dan kelompok kontrol, digunakan uji $t$ dependent. Hasil analisis uji tersebut dapat dilihat pada tabel 1 .

Tabel 1 menunjukkan kelompok kontrol kemandirian eliminasi anak, dan pengetahuan, sikap, keterampilan keluarga tentang toilet

Tabel 1 Rerata Kemandirian Eliminasi Anak, Pengetahuan, Sikap, Keterampilan Keluarga Sebelum dan Sesudah Diberi Modul

\begin{tabular}{llccccc}
\hline \multicolumn{1}{c}{ Variabel } & \multicolumn{1}{c}{ Kelompok } & \multicolumn{2}{c}{ Sebelum } & \multicolumn{2}{c}{ Sesudah } & p-value \\
\hline \multirow{2}{*}{ Kemandirian } & Mean & SD & Mean & SD & \\
Eliminasi Anak & Pengetahuan & 66,3 & 17,9 & 96,5 & 6,2 & 0,000 \\
& Kontrol & 63,7 & 15,8 & 70,9 & 13,3 & 0,010 \\
Pengetahuan & Perlakuan & 61,6 & 6,9 & 77,1 & 9,1 & 0,000 \\
& Kontrol & 63,4 & 10,6 & 57,3 & 11,3 & 0,030 \\
\multirow{2}{*}{ Sikap } & Perlakuan & 72,1 & 8,4 & 82,9 & 6,9 & 0,000 \\
& Kontrol & 74,8 & 8,3 & 71,2 & 8,9 & 0,020 \\
\hline Keterampilan & Perlakuan & 60,4 & 22,4 & 94,6 & 6,4 & 0,000 \\
\cline { 3 - 7 } Keluarga & Kontrol & 62,1 & 18,3 & 70,4 & 16,2 & 0,020 \\
\hline
\end{tabular}


Iryanti: Pengaruh Modul Pemberdayaan Keluarga tentang Toilet Training

Tabel 2 Pengaruh Modul Pemberdayaan Keluarga tentang Toilet Training terhadap Kemandirian Eliminasi Anak

\begin{tabular}{|c|c|c|c|c|c|}
\hline \multirow[t]{2}{*}{$\begin{array}{l}\text { Kemandirian } \\
\text { Eliminasi Anak }\end{array}$} & $\begin{array}{l}\text { Sebelum } \\
\text { (pretest) }\end{array}$ & $\begin{array}{l}\text { Sesudah } \\
\text { (posttest) }\end{array}$ & Delta $(\Delta)$ & $\mathbf{t}$ & P (Delta) \\
\hline & Mean + SD & Mean+ SD & & & \\
\hline Perlakuan & $66,3+17,9$ & $96,5+6,2$ & 30,2 & 6,940 & 0,000 \\
\hline Perlakuan & $63,7+15,8$ & $70,9+13,3$ & 7,2 & & \\
\hline
\end{tabular}

Tabel 3 Pengetahuan, Sikap, dan Keterampilan Keluarga terhadap Kemandirian Eliminasi Anak

\begin{tabular}{clccccc}
\hline No. & $\begin{array}{c}\text { Variabel } \\
\text { Independen }\end{array}$ & Koef Beta & SE & t & p-value & R Square \\
\hline 1 & Pengetahuan & 0,067 & 0,148 & 0,520 & 0,605 & 0,501 \\
2 & Sikap & 0,297 & 0,206 & 2,428 & 0,019 & \\
3 & Keterampilan & 0,462 & 0,118 & 3,738 & 0,000 & \\
& Keluarga & & & & & \\
\hline
\end{tabular}

training sebelum dan sesudah didapatkan $\mathrm{p}$ $>\alpha(\mathrm{p}>0,05)$ ini berarti tidak ada perbedaan yang signifikan kemandirian eliminasi anak, pengetahuan, sikap, keterampilan keluarga tentang toilet training sebelum dan sesudah. Sedangkan pada kelompok perlakuan kemandirian eliminasi anak, dan pengetahuan, sikap, keterampilan keluarga tentang toilet training sebelum dan sesudah didapatkan $\mathrm{p}<\alpha(\mathrm{p}<0,05)$ berarti ada perbedaan signifikan kemandirian eliminasi anak, pengetahuan, sikap, dan keterampilan keluarga tentang toilet training sebelum dan sesudah diberi modul.

Berdasarkan hasil uji normalitas, variabel kemandirian eliminasi anak sebelum perlakuan didapatkan nilai Skewness dibagi standar eror $<2$ maka data tersebut merupakan data yang berdistribusi normal, sehingga untuk menganalisis pengaruh modul pemberdayaan keluarga tentang toilet training terhadap kemandirian eliminasi anak di PAUD Kota Bandung, digunakan uji statistik T independent, Hasil analisis uji tersebut dapat dilihat pada tabel 2.

Berdasarkan tabel 2 didapatkan rerata nilai kemandirian eliminasi anak sesudah keluarga diberi modul tentang toilet training selama 4 minggu pada kelompok perlakuan lebih tinggi dari pada kelompok kontrol yaitu dengan selisih rerata nilai 25,6 poin, $p$-value $=0,000<\alpha(0,05)$, artinya penggunaan modul tentang toilet training oleh keluarga minimal 4 minggu berpengaruh terhadap peningkatan kemandirian eliminasi anak di PAUD Kota Bandung. Untuk melihat hubungan variabel antara yaitu pengetahuan, sikap, dan keterampilan keluarga dengan variabel terikat yaitu kemandirian eliminasi anak dilakukan uji regresi. Hasil uji Levene's data pengetahuan, sikap, dan keterampilan keluarga sebelum perlakuan didapatkan $p$-value pengetahuan $=0,101, p$-value sikap $=$ $0,635, \mathrm{p}$-value keterampilan keluarga $=0,112$, ketiga variabel tersebut $p$-value $>\alpha(0,05)$ artinya pengetahuan, sikap, dan keterampilan keluarga sebelum diberi modul tentang toilet training pada kelompok perlakuan dan kelompok kontrol adalah homogen, sehingga untuk menganalisis hubungan pengetahuan, sikap, dan keterampilan keluarga dengan kemandirian eliminasi anak di PAUD Kota Bandung digunakan uji regresi logistik linier. Hasil uji tersebut dapat dilihat pada tabel 3.

Berdasarkan tabel. 3 didapatkan p-value sikap $=0,019<\alpha(0,05)$ dan $\quad$-value keterampilan keluarga $=0,000<\alpha(0,05)$ yang bermakna secara statistik sebagai faktor yang berhubungan dengan terjadinya peningkatan rerata nilai kemandirian eliminasi anak. Hal ini menunjukkan bahwa sikap dan keterampilan keluarga memberikan kontribusi pada kenaikan rerata nilai kemandirian eliminasi anak, artinya keluarga yang memiliki sikap 
Iryanti: Pengaruh Modul Pemberdayaan Keluarga tentang Toilet Training

dan keterampilan yang baik tentang toilet training dapat memandirikan anak $\mathrm{BAB} /$ BAK di toilet.

\section{Pembahasan}

Hasil penelitian menunjukkan bahwa pemberian modul pada keluarga dapat meningkatkan pengetahuan keluarga tentang toilet training. Sejalan dengan pendapat Notoatmodjo bahwa pengetahuan dapat diperoleh melalui pembelajaran modul, karena pada dasarnya, pembelajaran dengan modul memberikan kesempatan kepada keluarga untuk belajar secara mandiri (Sungkono, 2013). Peningkatan pengetahuan disebabkan modul yang diberikan sudah cukup baik, hal ini sesuai dengan ungkapan dari keluarga pada saat posttest, bahwa modul menarik, simpel, dan komunikatif, serta didukung oleh tingkat pendidikan keluarga di mana 71,4 persen keluarga berpedidikan menengah ke atas. Kondisi ini menyebabkan kemampuan keluarga untuk memahami modul tentang toilet training menjadi baik.

Keluarga yang berpengetahuan baik berarti mempunyai pemahaman yang baik tentang manfaat dan dampak toilet training, sehingga keluarga akan mempunyai sikap yang positif terhadap konsep toilet training. Sikap merupakan kencenderungan seseorang untuk bertindak atau berperilaku (Suryabudhi, 2003 dalam Pusparini, 2010). Sesuai dengan pendapat Notoatmodjo, (2003 dalam Wijayanti dan Purwandari, 2006) bahwa pengetahuan merupakan domain yang sangat penting untuk terbentuknya tindakan seseorang. Selain itu, faktor pendidikan keluarga juga memengaruhi sikap keluarga, di mana keluarga dengan pendidikan menengah ke atas akan lebih baik dalam mempersepsikan sesuatu dibandingkan dengan keluarga yang berpendidikan dasar.

Menurut Salawati (2009), menjelaskan bahwa proses pembentukan sikap berlangsung secara bertahap melalui proses belajar sosial karena pengalaman pribadi dengan obyek tertentu. Sikap dipengaruhi oleh informasi yang diberikan orang lain yang telah memiliki atau membentuk sikap tertentu terhadap objek tertentu pula dari pengalaman langsung. Seseorang yang memperoleh informasi yang akurat dengan sendirinya memperoleh pengalaman langsung dengan objek tersebut. Akhirnya keluarga akan mempercayai informasi itu yang berakibat menciptakan terjadinya perubahan sikap.Perubahan sikap dapat berupa penambahan, pengalihan atau modifikasi dari satu atau lebih komponen, artinya ada kemungkinan satu atau dua komponen sikap itu berubah, tapi komponen lain tetap sama. Faktor pengalaman dan kematangan umur sangat berpengaruh dalam perubahan sikap seseorang.

Keluarga yang diberi modul tentang toilet training, keterampilan toilet trainingnya jauh lebih baik dibandingkan dengan keluarga yang tidak diberi modul. Meningkatnya keterampilan keluarga tersebut berkaitan dengan peningkatan pengatahuan dan sikap keluarga tentang toilet training. Hasil penelitian tersebut sejalan penelitian Pusparini (2010), yang menyimpulkan bahwa pengetahuan terbukti memiliki hubungan dengan perilaku ibu dalam melatih toilet training pada anak usia toddler.

Pada penelitian ini keluarga terbanyak adalah bekerja sebagai ibu rumah tangga. Kondisi tersebut menyebabkan keluarga memiliki waktu yang cukup untuk memberi perhatian kepada anaknya. Faktor lingkungan rumah, dimana keluarga memiliki waktu luang yang cukup dalam berinteraksi dengan anaknya menjadi lebih baik. Kondisi ini membantu keluarga memperhatikan perkembangan perilaku anaknya, khususnya dalam pemberian toilet training.

Sehubungan dengan hal di atas, maka pemberian modul pada keluarga terbukti dapat meningkatkan pengetahuan, komponenkomponen sikap, dan keterampilan keluarga, sehingga modul tentang toilet training ini dapat dipertimbangkan sebagai salah satu model yang perlu diberikan kepada keluarga yang memiliki anak umur prasekolah yang belum dapat mengotrol $\mathrm{BAB} / \mathrm{BAK}$ secara mandiri di toilet.

Pengaruh modul pemberdayaan keluarga tentang toilet training terhadap kemandirian eliminasi anak, hasil penelitian menunjukkan kemandirian eliminasi anak pada keluarga yang diberi modul tentang toilet training selama 4 minggu terjadi peningkatan, hal tersebut dapat dilihat dari selisih rerata nilai sesudah perlakuan antara kelompok 
Iryanti: Pengaruh Modul Pemberdayaan Keluarga tentang Toilet Training

perlakuan dengan kelompok kontrol terdapat selisih 25,6 poin, artinya modul tentang toilet training yang diberikan kepada keluarga mempunyai pengaruh terhadap peningkatan kemandirian eliminasi anak.

Hal ini disebabkan karena pada kelompok perlakuan, keluarga diberi modul tentang cara melatih $\mathrm{BAB} / \mathrm{BAK}$ secara lisan dan modeling tentang toilet training. Modeling tidak sekedar peniruan atau mengulangi perilaku model tetapi modeling melibatkan penambahan dan atau pengurangan tingkah laku yang teramati, menggeneralisir berbagai pengamatan sekaligus melibatkan proses kognitif. Teori belajar sosial yang dikemukakan oleh Bandurayang menekankan bahwa lingkungan yang dihadapkan pada seseorang secara kebetulan, lingkungan itu seringkali dipilih dan diubah oleh orang itu melalui perilakunya sendiri (Yusuf, 2011). Inti dari pembelajaran sosial adalah permodelan, merupakan salah satu langkah paling penting dalam pembelajaran terpadu (Hall \& Lindzey, 2012). Sesuai dengan teori toilet training yaitu ada 2 teknik yang dapat dilakukan dalam melatih anak untuk BAK /BAB yaitu teknik lisan dan modeling. Teknik modeling merupakan usaha melatih anak dalam melakukan BAK/ BAB dengan cara meniru atau memberi contoh atau membiasakan BAK/BAB secara benar (Hidayat, 2009). Sejalan dengan penelitian Keen et al., (2007) dalam Toilet training for children with autism: the effects of video modeling menunjukkan bahwa model video dapat meningkatkan pencapaian BAK di siang hari di kalangan anak-anak autism. Frekuensi BAK di toilet lebih besar bagi anak-anak autis yang menonton video toilet training dibandingkan anak-anak yang tidak menonton. Penjelasan di atas menyimpulkan bahwa keluarga yang diberi modul tentang Toilet training yaitu modul yang berisi cara melatih $\mathrm{BAB} / \mathrm{BAB}$ anak dengan cara lisan dan modeling berpengaruh terhadap peningkatan kemampuan anak mengontrol $\mathrm{BAB} / \mathrm{BAK}$ secara mandiri di toilet.

Pada penelitian ini juga dilakukan analisis untuk mengetahui hubungan variabel antara yaitu pengetahuan, sikap, dan keterampilan keluarga setelah diberi modul tentang toilet training dengan variabel terikat yaitu kemandirian eliminasi anak dengan analisis logistik linier. Hasil analisis menunjukkan bahwa faktor sikap, dan keterampilan keluarga yang bermakna secara statistik sebagai faktor yang berhubungan dengan peningkatan kemandirian eliminasi anak, artinya keluarga yang memiliki sikap dan keterampilan yang baik tentang toilet training akan meningkatkan kemampuan anak dalam mengotrol keinginan $\mathrm{BAB} / \mathrm{BAK}$ secara mandiri di toilet. Jika dilihat dari koefisien beta, maka keterampilan keluarga yang paling tinggi yaitu 0,462 yang artinya keterampilan keluarga merupakan faktor yang paling besar pengaruhnya terhadap kemandirian eliminasi anak.

Hasil penelitian tersebut sejalan dengan pendapat Gupte (2004 dalam Ammelda, dkk. 2015) bahwa usaha untuk melatih anak dalam BAB/BAK dapat dilakukan dengan cara memberikan contoh, memberikan pujian saat anak berhasil dan tidak memarahi saat anak gagal dalam melakukan toilet training, dengan memberi contoh anak akan menirukan dengan benar. Anak kemungkinan tidak langsung memberikan respon atau perilaku yang langsung dapat diobservasi, tetapi anak menyimpan apa yang diobservasinya tersebut dalam bentuk kognitifnya. Bentuk kognitif ini tetap aktif dalam diri anak dan pada saat anak berada pada situasi atau kondisi yang serupa, secara spontan bentuk kognitif tadi turut serta menentukan perilaku si anak dalam kondisi tersebut. Perilaku model yang telah diobservasi anak menjadi referensi bawah sadar, yang apabila anak bertemu dengan situasi serupa kelak akan memberikan respons seperti dia telah melihat bagaimana modelnya memberi respon (Alwisol, 2009).

Hasil uji statistik didapatkan $R$ Square 0,501 , artinya modul tentang toilet training ini dapat memberdayakan keluarga dalam memandirikan eliminasi anak sebanyak 50,1 persen. Artinya model lain dapat berkontribusi terhadap kemandirian eliminasi anak. Perawat sebagai tenaga kesehatan memiliki tanggung jawab untuk mempromosikan kesehatan keluarga dan anak, menyediakan layanan pada klien yang meliputi dukungan, pendidikan kesehatan dan pelayanan keperawatan yang dapat berkontribusi dalam meningkatkan pengetahuan, sikap dan keterampilan ibu dalam merawat anaknya (Mercer, 2006). Perawat dapat bermitra dengan keluarga 
Iryanti: Pengaruh Modul Pemberdayaan Keluarga tentang Toilet Training

dan kader untuk melakukan pembinaan tumbuh kembang anak secara komprehensif dan berkualitas melalui kegiatan stimulasi atau latihan, deteksi dan intervensi dini penyimpangan tumbuh kembang balita, agar kualitas tumbuh kembang balita meningkat dan balita siap memasuki jenjang pendidikan formal. Selain itu, keperawatan juga merupakan profesi kesehatan yang berinteraksi kuat dan mendukung wanita dalam pencapaian peran sebagai agen kesehatan bagi anak dan keluarganya.

\section{Simpulan}

Hasil penelitian didapatkan bahwa rerata pengetahuan, sikap, keterampilan keluarga dan kemandirian eliminasi anak yang diberi modul tentang toilet training terjadi peningkatan yang bermakna dibandingkan dengan keluarga yang tidak diberi modul artinya pemberdayaan keluarga tentang toilet training terbukti dapat berpengaruh secara signifikan pada peningkatan kemandirian eliminasi anak. Hasil penelitian juga menunjukkan bahwa sikap dan keterampilan keluarga memberikan kontribusi pada kenaikan rerata kemandirian eliminasi anak, artinya keluarga atau orang yang dominan dalam pengasuhan anak yang memiliki sikap dan keterampilan yang baik tentang toilet training dapat memandirikan anak $\mathrm{BAB} /$ BAK di toilet.

Berdasarkan kesimpulan terebut, maka saran yang dapat disampaikan untuk meningkatkan kemandirian eliminasi anak adalah: bagi PAUD atau praktisi kesehatan dapat memfasilitasi keluarga yang memiliki anak lebih dari 3 tahun yang masih $\mathrm{BAB} / \mathrm{BAK}$ di celana, untuk mendapatkan penyuluhan baik melalui modul atau video secara kontinyu agar pengetahuan, sikap, dan keterampilan keluarga meningkat sehingga keluarga punya kemampuan untuk melakukan toilet training pada anaknya dengan baik dan benar; modul pemberdayaan keluarga tentang toilet training dapat dipertimbangkan sebagai salah satu alternatif dalam upaya memandirikan eliminasi BAB/BAK anak di toilet; agar pemberian modul tentang toilet training ini efektif meningkatkan pengetahuan, sikap, dan keterampilan keluarga, diperlukan modul yang menarik terutama dari segi materi, gambar, serta komunikatif; keluarga hendaknya meningkatkan pengetahuan, sikap, dan keterampilan tentang toilet training, karena dengan pengetahuan, sikap, dan keterampilan yang keluarga miliki keluarga akan mampu melakuan toilet training pada anaknya dengan baik dan benar.

\section{Daftar Pustaka}

Adriana, D. (2011). Tumbuh kembang dan terapi bermain pada anak. Jakarta: Salemba Medika.

Alexandra, V. (2008). Toilet training of healthy young toddlers: A randomized trial between a daytime wetting alarm and timed potty training. Journal of Developmental \& Behavior Pediatrics, 29(3), 191-196.

Alwisol.(2009). Psikologi Kepribadian. Edisi revisi. Malang: Universitas Muhammadyah Malang.

Ammelda, R., Novayelinda, R., \& Erwin. (2015). Pengaruh modeling media video dan gambar terhadap peningkatan kemampuan toilet training pada anak toodler. Tersedia dalam Repository.unri.ac.id/ xmlui/ bitstream /handle/123456789/4139/jurnal. pdf? sequence $=1$. Diunduh tanggal 28 Pebruari 2015.

Barone, J. G. (2009). Later toilet training is associated with urge incontinence in children. Journal of Pediatric Urology, 5(6), 458-461.

Grove, S. K., Burn, N., \& Gray, J. R. (2013). The practice of nursing research: Appraisal, synthesis, and generation of evidence. $7^{\text {th }}$ edition. St.Louis Missouri: Elsevier Sounders.

Hall, C. S., \& Lindzey, G. (2012). Teori-teori sifat dan behavioristik. Yogyakarta: Kanisius.

Hastono, S. P. (2007). Analisis data kesehatan: Basic data analysis for health research training. Jakarta: Fakultas Kesehatan Masyarakat Universitas Indonesia.

Hidayat, A. Aziz. (2009). Pengantar ilmu 
Iryanti: Pengaruh Modul Pemberdayaan Keluarga tentang Toilet Training

kesehatan anak 1. Jakarta: Salemba Medika.

Hidayat, I. H. (2010). Gambaran pengetahuan ibu tentang toilet training pada anak usia prasekolah/TK di TK Al-Azhar Medan. Tersedia dalam Universitashttp://repository. usu.ac.id/bitstream/123456789/23318/4/ Chapter\%20II.pdf.

Horn, I. B. (2006). Beliefs about the appropriate age for initiating toilet training: Are there racial and socioeconomic differences?. The Journal of Pediatrics, 149(2), 165-168.

Kemenkes, R. I. (2012). Pedoman pelaksanaan stimulasi, deteksi dan intervensi dini tumbuh kembang anak di tingkat pelayanan kesehatan dasar. Jakarta: Direktorat Bina Kesehatan Anak Direktorat Jenderal Bina Kesehatan Masyarakat Departemen Kesehatan RI.

Keen, D., Brannigan, K.L., \& Cruskelly, M. (2007). Toilet training for children with Autism: The effects of video modeling. Journal of Development and Physical Disabilities, 19(4), 291-303.

Klijn, A. J. (2006). Home uroflowmetry biofeedback in behavioral training for dysfunctional voiding in school-age children: A randomized controlled study. The Journal of Urology, 17(56), 2263-2268.

Kurniawati, E. (2008). Enuresis. Buletin penelitian RSU Dr. Soetomo,89-9.

Kroeger, K. (2010). A parent training model for toilet training children with autism. Journal of In $\neg$ tellectual Disability Research, 54(6), 556-567.

Mercer, T.R. and Walker, L.O. 2006. A review of nursing intervention to fosterbecoming a mother. AWHONN. JOGNN, 35(5).

Mota, D. M., \& Barros, A. J. D. (2008). Toilet training: methods, parental expectations and associated dysfunctions. Journal de Pediatria, 84(1).

Pusparini, W. (2010). Hubungan pengetahuan ibu tentang toilet training dengan perilaku ibu dalam melatih toilet training pada anak umur toddler di Desa Kadokan Sukoharjo. Tersedia dalam Eprints.ums.ac.id/9476/1/ K210060033.pdf. Diunduh tanggal 2 Nopember 2015.

Salawati, L. (2009). Hubungan perilaku, manajemen keselamatan dan kesehatan kerja dengan terjadi kecelakaan kerja di Laboratorium Patologi Klinik Rumah Sakit Umum DR. Zainoel Abidin Banda Aceh. Tersedia dalam http://www.academia. edu/19735978. Diunduh tanggal 16 Mei 2916

Shankar, P. R., Singh, K. K., \& Priyani, R. M. (2012). Knowledge, attitude and skills before and after a module on pharmaceutical promotion in a Nepalese medical school. BMC Research Notes. Tersedia dalam, http:// www.biomedcentral.com/1756-0500/5/8. Diunduh tanggal 12 Mei 2016.

Sungkono. (2013). Pengembangan dan pemanfaatan bahan ajar modul dalam proses pembelajaran. Tersedia dalam https:// andridm72.wordpress.com /ilmu/, Diunduh tanggal 2 Pebruari 2015.

Suyatno. (2010). Menghitung besar sampel penelitian kesehatan masyarakat. blog.undip. ac.id. Diunduh 24 Maret 2016.

Syahid, L. (2009). Hubungan antara tingkat pengetahuan ibu tentang toilet training dengan penerapan toilet training pada anak umur toddler di Kelurahan Mijen Kecamatan Mijen Kota Semarang (Skripsi). Universitas Muhammadiyah Semarang, Semarang.

Wald, E. R. (2009). Bowel habits and toilet training in a diverse population of children. Journal of Pediatric Gastroenterology \& Nutrition, 48(3), 294-298.

Warner, P., \& Paula, K. ( 2007). Mengajari anak pergi ke toilet. Jakarta: Arcan

Wijayanti, R., \& Purwandari, H. (2006). Dampak penggunaan modul terhadap peningkatan pengetahuan dan keterampilan keluarga dalam menstimulasi tumbuh kembang bayi. Jurnal Keperawatan Sudirman 
Iryanti: Pengaruh Modul Pemberdayaan Keluarga tentang Toilet Training

(The Soedirman Journal of Nursing), 1(2). anak dan remaja. Bandung: PT. Remaja Yusuf, S. (2011). Psikologi perkembangan Rosdakarya. 